\title{
A Comparison of Insulin Pen Devices and Disposable Plastic Syringes - Simplicity, Safety, Convenience and Cost Differences
}

\author{
Ripudaman Singh, ${ }^{1}$ Clarence Samuel $^{2}$ and Jubbin J Jacob ${ }^{1}$ \\ 1. Endocrine and Diabetes Unit, Department of Medicine, Christian Medical College and Hospital, Ludhiana, Punjab, India; \\ 2. Department of Community Health, Christian Medical College and Hospital, Ludhiana, Punjab, India
}

\begin{abstract}
$\mathrm{C}$ ontext: Managing diabetes efficiently demands a simple, safe, convenient and economical therapy. This study was done to understand the simplicity, safety, convenience and cost effectiveness of using pen versus syringe devices in patients on long-term insulin therapy. Design: This prospective observational study was conducted at the endocrine outpatient department of a universityaffiliated teaching hospital in North India. The investigator interviewed patients using a self-made questionnaire after obtaining consent; patients were scored based on their answers. A high score represented a poor response. A total of 90 completed questionnaires ( 45 from each group) were obtained. Results: Mean simplicity, safety and convenience score among the pen users was $5.31 \pm 0.51,5.4 \pm 0.89$ and $4.13 \pm 1.04$ respectively, as compared to $9.78 \pm 1.43,8.09 \pm 2.02$ and $8.67 \pm 0.56$ in syringe users respectively. The difference in these scores was statistically significant $(\mathrm{p}=0.0001)$. All patients felt that treatment using pen device was costlier when compared to using syringes, with pen users spending Rs1,756 per month on their insulin therapy, as compared to syringe users, who spent Rs590 per month. Among insulin pen users, $22.2 \%$ had optimal glycated haemoglobin levels (6-7.5\%) as compared to $2.2 \%$ among syringe users, and this difference was statistically significant $(\mathrm{p}=0.007)$. Conclusions: An insulin pen is simple, safe and convenient to use, and may provide better glycaemic control. Treatment with a pen device is costlier, which may be due to the higher use of analogue insulin among pen users.
\end{abstract}

\section{Keywords}

Insulin use, pen device, insulin pen, insulin syringes

Disclosure: Ripudaman Singh, Clarence Samuel and Jubbin J Jacob have nothing to declare in relation to this article.

Review Process: Double-blind peer review.

Acknowledgement: First of all, the authors would like to thank all the patients who participated in the research at the Christian Medical College and Hospital, Ludhiana. The authors would also like to express gratitude towards the diabetes specialist nurse (Mrs Nisha Mathew) and to the clinic physician assistant (Mrs Ribeka Masih) for helping them in recruiting patients and in data collection.

Compliance with Ethics: All procedures were followed in accordance with the responsible committee on human experimentation and with the Helsink Declaration of 1975 and subsequent revisions.

Authorship: All named authors meet the International Committee of Medical Journal Editors (ICMJE) criteria for authorship of this manuscript, take responsibility for the integrity of the work as a whole, and have given final approval to the version to be published.

Open Access: This article is published under the Creative Commons Attribution Noncommercial License, which permits any non-commercial use, distribution, adaptation and reproduction provided the original author(s) and source are given appropriate credit. (C) The Authors 2018.

Received: 22 January 2018

Accepted: 16 February 2018

Citation: European Endocrinology. 2018;14(1):47-51

Corresponding Author: Jubbin Jagan Jacob, Endocrine and Diabetes Unit, Department of Medicine, Christian Medical College and Hospital, Ludhiana, Punjab 161008, India. E: jubbin.jacob@gmail.com

Support: Departmental intramural funding
Diabetes mellitus is a worldwide epidemic disease, which requires continuous long-term medical care. In addition, a considerable degree of engagement is required by the patient in his or her disease management. India is now considered the diabetes capital of the world. ${ }^{1}$ The total number of people expected to suffer from diabetes will double globally from 425 million in 2017 to 629 million in 2045. It is estimated that, by 2045, 134.3 million individuals will be affected by diabetes in India, suggesting that there will be a significant increase in the population burden of disease. China (119.8 million) and the US (35.6 million) will face a much smaller rise in the numbers of people affected by diabetes. ${ }^{2}$

With the introduction of insulin to treat diabetes, a significant improvement was seen in outcomes and patients were able to achieve better glycaemic control. Better glycaemic control in turn reduces the incidence of micro- and macrovascular complications such as neuropathy, retinopathy, nephropathy and cardiovascular diseases. ${ }^{3}$ Regardless of the known benefits of insulin, physicians and patients are reluctant to practice this 'complex therapy.. ${ }^{4}$ One out of four patients requiring insulin may refuse therapy due to psychological insulin resistance (PIR)..$^{5}$ In an Indian survey of 198 patients with type 2 diabetes, the major factors contributing to not starting insulin were found to be pain during injection, fear of injection and/or hypoglycaemia, social stigma and lack of education. ${ }^{6}$ With the introduction of insulin pens, patient's perceptions of insulin therapy have gradually improved and most are able to overcome the barriers stated earlier. ${ }^{7}$ The recent Forum for Injection Technique and Therapy (FITT) expert panel on insulin injection techniques has elegantly summarised ways to address many of the barriers to insulin use. ${ }^{8}$

This observational study was conducted with patients with diabetes mellitus in North India, to understand the simplicity, safety and acceptability of insulin among patients who use pen devices for insulin delivery versus patients who use a conventional insulin vial with disposable plastic syringes. In addition, the study also took into account the cost effectiveness of the available pen devices versus disposable syringes, since India is a developing country and treating diabetes successfully demands a simple but, at the same time, cost-effective therapy.

\section{Materials and methods}

Study setting and study population

This cross-sectional observational study was conducted in the diabetes and endocrine clinic at a university-affiliated tertiary referral hospital for a period of 12 months. All patients with 
diabetes, who were on insulin therapy and coming in for follow up were asked if they were willing to participate in this study and were divided into two groups. One group consisted of patients injecting insulin with the use of a pen device, and the other consisted of patients injecting insulin with the use of a disposable insulin syringe. Patients from each group who gave informed consent were interviewed personally by the investigator using a self-designed questionnaire (see Tables 1-3). A pilot study was done using this questionnaire, in order to validate the questionnaire. After this, the study and the methodology was approved by the institutional research and ethics committee.

\section{Inclusion and exclusion criteria}

All patients diagnosed with type 1 and type 2 diabetes mellitus aged 16 years or older from both genders were offered a chance to participate in the study. Patients had to be using insulin either by pen or a syringe device at least once a day or for at least six months at the time of inclusion. Patients who practised self-injection and those receiving help from family members to inject insulin were included in the study.

Pregnant women taking insulin for gestational diabetes, patients using insulin pumps, patients with known psychiatric illness and patients in whom daily injections were administered by health care professionals were excluded.

\section{Questionnaire development}

A structured questionnaire was designed by the investigators (Ripudaman Singh and Jubbin J Jacob) for data collection, modifying a similar invalidated questionnaire used by Ramadan et al. among patients in Lebanon. ${ }^{9}$ The study questionnaire was divided into seven segments. The first segment consisted of general questions about the patient's demographics as well as the type of diabetes and its duration, the duration of insulin use, the number of times blood glucose was self-monitored and the presence of any other comorbidities. The second segment had questions on the type of insulin use, method of insulin administration and the total daily insulin consumption. The third segment was designed to check the glycaemic control of these patients by reviewing the latest glycated haemoglobin $\left(\mathrm{HbA}_{1} \mathrm{c}\right)$ levels in their medical records.

The fourth and fifth segments consisted of five questions each on simplicity and safety. Simplicity was assessed by asking what the total number of missed doses were in the five days preceding the interview, the ease of handling the device/insulin during calibration of the dose, the ease of changing needles and the ease of insulin storage (Table 1). Safety was assessed by asking how painful was the process of injecting the insulin, the number of bruising episodes noted in the 5 days preceding the interview, the number of self-reported episodes of hyperglycaemia in the week preceding the interview, the number of hypoglycaemic episodes during last 3 months preceding the interview and recollection of the number of insulin cartridges/vials accidentally broken in the 12 months preceding the interview (Table 2).

The sixth segment had three questions on convenience, which was assessed by asking the total number of steps and the time taken to administer insulin. Additionally, the questionnaire enquired about the ease of administering insulin on trips and events/meals outside of the subject's home (Table 3). The seventh segment enquired about the cost of treatment by asking each patient the average cost of their therapy per month and their opinion on their current total cost of insulin therapy (insulin, disposables and cleaning equipment).
Table 1: Questionnaire for assessing simplicity of insulin delivery device

\begin{tabular}{|c|c|c|c|}
\hline \multicolumn{4}{|c|}{ Simplicity assessment questions } \\
\hline S No & Question & Options & Score* \\
\hline \multirow[t]{3}{*}{1} & \multirow{3}{*}{$\begin{array}{l}\text { How many of doses of insulin have } \\
\text { you missed in the last } 5 \text { days? }\end{array}$} & None & 1 \\
\hline & & $1-3$ doses & 2 \\
\hline & & $>3$ doses & 3 \\
\hline \multirow[t]{3}{*}{2} & \multirow[t]{3}{*}{ How easy is to inject your insulin? } & Easy & 1 \\
\hline & & Intermediate & 2 \\
\hline & & Hard & 3 \\
\hline \multirow[t]{3}{*}{3} & \multirow{3}{*}{$\begin{array}{l}\text { How easy is it to calibrate the dose of } \\
\text { your insulin? }\end{array}$} & Easy to learn & 1 \\
\hline & & Acceptable & 2 \\
\hline & & Hard & 3 \\
\hline \multirow[t]{3}{*}{4} & \multirow{3}{*}{$\begin{array}{l}\text { How easy is it to change needles } \\
\text { (removing/connecting)? }\end{array}$} & Easy & 1 \\
\hline & & Acceptable & 2 \\
\hline & & Hard & 3 \\
\hline \multirow[t]{3}{*}{5} & \multirow[t]{3}{*}{ How easy is it to store your insulin? } & Easy & 1 \\
\hline & & Acceptable & 2 \\
\hline & & Hard & 3 \\
\hline
\end{tabular}

*Scoring as per response. Minimum score of 5, maximum score of 15. Lower score indicates simpler device and a higher score denotes a more complicated device.

Table 2: Questionnaire for assessing safety of insulin delivery device

\begin{tabular}{|c|c|c|c|}
\hline \multicolumn{4}{|c|}{ Safety assessment questions } \\
\hline S No & Question & Options & Score $^{*}$ \\
\hline \multirow[t]{3}{*}{1} & \multirow{3}{*}{$\begin{array}{l}\text { How painful is the process of injecting } \\
\text { your insulin? }\end{array}$} & Acceptable pain & 1 \\
\hline & & Bearable pain & 2 \\
\hline & & Unbearable pain & 3 \\
\hline \multirow[t]{3}{*}{2} & \multirow{3}{*}{$\begin{array}{l}\text { How many bruising episodes at } \\
\text { injection sites have you had in the } \\
\text { last } 5 \text { days? }\end{array}$} & None & 1 \\
\hline & & 1 episode & 2 \\
\hline & & $>1$ episode & 3 \\
\hline \multirow[t]{3}{*}{3} & \multirow{3}{*}{$\begin{array}{l}\text { How many episodes of high sugars } \\
\text { (your perception) have you noticed in } \\
\text { the last one week? }\end{array}$} & None & 1 \\
\hline & & 1 episode & 2 \\
\hline & & $>1$ episode & 3 \\
\hline \multirow[t]{3}{*}{4} & \multirow{3}{*}{$\begin{array}{l}\text { How many episodes of low sugars } \\
\text { (your perception) have you noticed in } \\
\text { the last one week? }\end{array}$} & None & 1 \\
\hline & & 1 episode & 2 \\
\hline & & >1 episode & 3 \\
\hline \multirow[t]{3}{*}{5} & \multirow{3}{*}{$\begin{array}{l}\text { How many times have your broken } \\
\text { your insulin vial/cartridge in the past } \\
\text { one year? }\end{array}$} & None & 1 \\
\hline & & 1 episode & 2 \\
\hline & & $>1$ episode & 3 \\
\hline
\end{tabular}

* Scoring as per response. Minimum score of 5, maximum score of 15. Lower score indicates safer device and a higher score denotes a more unsafe device.

Each patient was interviewed personally by the investigator, who filled in the questionnaire based on the answers given by the patient. Each answer was given a score. The highest obtainable score for simplicity and safety was 15 , whereas for convenience it was 9 . The scoring system was designed to place the responses in a descending order, such that higher scores depicted a poorer response.

The questionnaire was tested by the investigator in a pilot study among 15 patients (eight syringe users and seven pen users) prior to study approval. Based on feedback, some of the questions were modified. Subsequently, the questionnaire and the study methods were approved by the institutional research and ethics committee. 
Table 3: Questionnaire for assessing convenience of insulin delivery device

\begin{tabular}{|c|c|c|c|}
\hline \multicolumn{4}{|c|}{ Convenience assessment questions } \\
\hline S No & Question & Options & Score* \\
\hline \multirow[t]{3}{*}{1} & \multirow{3}{*}{$\begin{array}{l}\text { How much time do you spend in } \\
\text { injecting insulin once the insulin is at } \\
\text { room temperature? }\end{array}$} & $<1 \mathrm{~min}$ & 1 \\
\hline & & $1-2$ mins & 2 \\
\hline & & $>2$ mins & 3 \\
\hline \multirow[t]{3}{*}{2} & \multirow{3}{*}{$\begin{array}{l}\text { How many steps you have to } \\
\text { remember to take when you inject } \\
\text { your insulin? }\end{array}$} & $<2$ & 1 \\
\hline & & $2-4$ & 2 \\
\hline & & $>4$ & 3 \\
\hline \multirow[t]{3}{*}{3} & \multirow{3}{*}{$\begin{array}{l}\text { How easy is it to carry insulin on } \\
\text { holidays and for meals outside the } \\
\text { home? }\end{array}$} & Easy & 1 \\
\hline & & Acceptable & 2 \\
\hline & & Hard & 3 \\
\hline
\end{tabular}

*Scoring as per response. Minimum score of 3, maximum score of 9. Lower score indicates a more convenient device and a higher score denotes an inconvenient device.

\section{Statistical analysis}

A minimum sample of 60 patients (30 pen users and 30 syringe users) was determined for statistical significance using the difference in responses in the pilot study. The complete data obtained from all participants were entered in a Microsoft Excel sheet. Significant differences between sociodemographic factors and the various scores were assessed by performing a chi-square test for categorical variables and the students' $T$ test for continuous variables. Significance was defined as $p<0.05$ and all analysis was performed on Statistical Package for the Social Sciences (SPSS V.21).

\section{Results}

A total of 90 patients using insulin therapy for at least six months gave informed consent and were included in the study. Half the patients were using insulin pens for injecting insulin and the other half used disposable insulin syringes with insulin vials.

The baseline data is summarised in Table 4. More men were using insulin pen device as compared to disposable syringes $(p=0.140)$ and the majority of patients who were using insulin syringes had used insulin syringes for over 10 years $(p=0.79)$. However, both these differences were not statistically significant.

The average amount of insulin units administered per day was $44 \pm 25.4$ IU/day among insulin pen users, which was higher as compared to $37 \pm 17.4 \mathrm{IU} /$ day among insulin syringe users $(p=0.812$ ). Among the different types of insulin used, premixed insulin was used in a greater proportion of patients in both the groups (48.9\% among insulin pen users and $62.2 \%$ among insulin syringe users).

About 22\% of patients using an insulin pen device had optimal levels of $\mathrm{HbA}_{1} \mathrm{C}$ (i.e. 6-7.5\%) which was higher as compared to $2.2 \%$ among insulin syringe users group. This difference in percentage was found to be statistically significant ( $p=0.007$ ). The percentages of patients with optimal and poor $\mathrm{HbA}_{1} \mathrm{C}$ levels in both groups are represented in Figure 1. Mean simplicity, safety and convenience score among the pen and syringe users is shown in Table 5.

Almost all patients in both the groups felt that using the pen device for insulin administration was more expensive as compared to a disposable syringe device. The average expenditure of insulin therapy per month among pen users was Rs1,756 (Rs 1.33 per unit), which
Table 4: Baseline data of all patients

\begin{tabular}{|c|c|c|c|}
\hline & $\begin{array}{l}\text { Disposable } \\
\text { syringe users }\end{array}$ & $\begin{array}{l}\text { Insulin pen } \\
\text { users }\end{array}$ & $\mathrm{p}$-value \\
\hline Number of patients & 45 & 45 & \\
\hline $\begin{array}{l}\text { Male } \\
\text { Female }\end{array}$ & $\begin{array}{l}18(40 \%) \\
27(60 \%)\end{array}$ & $\begin{array}{l}20(55.6 \%) \\
20(44.4 \%)\end{array}$ & 0.140 \\
\hline $\begin{array}{l}\text { Age in years } \\
\begin{array}{l}18-35 \\
36-60 \\
>60\end{array}\end{array}$ & $\begin{array}{l}09 \text { (20\%) } \\
18(40 \%) \\
18(40 \%)\end{array}$ & $\begin{array}{l}10(22.2 \%) \\
20(44.4 \%) \\
15(33.3 \%)\end{array}$ & 0.806 \\
\hline $\begin{array}{l}\text { Type of diabetes mellitus } \\
\text { Type } 1 \\
\text { Type } 2\end{array}$ & $\begin{array}{l}17(37.8 \%) \\
28(62.2 \%)\end{array}$ & $\begin{array}{l}15(33.3 \%) \\
30(66.7 \%)\end{array}$ & 0.660 \\
\hline $\begin{array}{l}\text { Duration of diabetes (years) } \\
\begin{array}{l}0-10 \\
11-20 \\
>20\end{array}\end{array}$ & $\begin{array}{l}23(51.1 \%) \\
17(37.8 \%) \\
05(11.1 \%)\end{array}$ & $\begin{array}{l}27(60 \%) \\
13(28.9 \%) \\
05(11.1 \%)\end{array}$ & 0.653 \\
\hline $\begin{array}{l}\text { Duration of insulin use (years) } \\
\begin{array}{l}0-10 \\
11-20 \\
>20\end{array}\end{array}$ & $\begin{array}{l}38(84.4 \%) \\
07(15.6 \%) \\
00\end{array}$ & $\begin{array}{l}43(95.6 \%) \\
02(4.4 \%) \\
00\end{array}$ & 0.79 \\
\hline $\begin{array}{l}\text { Self-glucose monitoring (per day) } \\
\text { Once } \\
\text { Twice } \\
\text { >2 times }\end{array}$ & $\begin{array}{l}33(73.3 \%) \\
10(22.2 \%) \\
02(4.4 \%)\end{array}$ & $\begin{array}{l}28(62.2 \%) \\
14(31.1 \%) \\
03(6.7 \%)\end{array}$ & 0.528 \\
\hline $\begin{array}{l}\text { Presence of comorbidities } \\
\text { Yes } \\
\text { No }\end{array}$ & $\begin{array}{l}27(60 \%) \\
18(40 \%)\end{array}$ & $\begin{array}{l}27(60 \%) \\
18(40 \%)\end{array}$ & 1.0 \\
\hline $\begin{array}{l}\text { Mean Insulin dose per day } \\
\text { Total units/day }\end{array}$ & 37 & 44 & 0.34 \\
\hline $\begin{array}{l}\text { Type of insulin used } \\
\text { Basal insulin }{ }^{*} \\
\text { Basal plus insulin } \\
\text { Premixed insulin (twice daily) } \\
\text { Premixed insulin (three times } \\
\text { daily) }^{\infty} \\
\text { Basal/bolus insulin }^{\alpha}\end{array}$ & $\begin{array}{l}9(20 \%) \\
0(0 \%) \\
28(62.2 \%) \\
7(15.5 \%) \\
1(2.2 \%)\end{array}$ & $\begin{array}{l}6(13.3 \%) \\
6(13.3 \%) \\
22(48.8 \%) \\
11(24.4 \%) \\
0(0 \%)\end{array}$ & 0.47 \\
\hline
\end{tabular}

¥Includes basal analogue insulin and Insulin neutral protamine hegedron; ${ }^{\beta}$ All patients were on analogue insulins; “ Includes human premixed and analogue premixed insulins; 'Basal insulins were all analogue while meal time insulin was human insulin.

was higher as compared to Rs590 (Rs0.5 per unit) among disposable syringe users.

\section{Discussion}

Diabetes mellitus is a chronic disease which not only affects the health of an individual, but also imposes psychological impacts on their lives. ${ }^{10}$ It also greatly affects the quality of life of an individual. ${ }^{11}$

The treatment of diabetes involves the use of insulin, which is currently available primarily in an injectable form. Insulin helps to achieve better glycaemic control and significantly reduce the occurrence of diabetes-related complications. ${ }^{3}$ Despite its known benefits, the use of insulin is not easily accepted by patients due to the discomfort, social stigma and fear of hypoglycaemia associated with it. ${ }^{8}$ Every patient on insulin therapy is required to engage in frequent glucose monitoring, routine physician visits, daily monitoring of their calorie intake, and lifestyle modifications.

Since the effective treatment of diabetes utilises long-term and continuous adherence to insulin therapy, there is a need to consider 
Figure 1: Percentage of patients in both groups (pen users versus syringe users) with their $\mathrm{HbA}_{1} \mathrm{c}$ levels



Patients are divided into four groups. Group 1 with optimal glycemic control (6.0-7.4\%) (42-56 mmol/mol), Group 2 with suboptimal control (7.5-8.4\%) (57-68 mmol/mol), Group 3 with poor control (8.5-9.9\%) (69-85mmol/mol) and Group 4 with very poor control $(\geq 10 \%)(\geq 86 \mathrm{mmol} / \mathrm{mol})(p<0.007)$.

patients' preference for the type of insulin therapy. Currently, two insulin delivery devices, namely insulin pen and insulin syringe device, respectively, are commonly used.

Our study targeted several outcomes to compare insulin pen and insulin syringe devices in terms of simplicity, safety and convenience to use, also taking into account the cost effectiveness of each device. We found out that patients using the insulin pen device found it easier to learn to calibrate the dose, change the needles and store their pen device as compared to syringe users, making pen devices simple to use. Similar results were seen in a study done in Lebanon, where a higher percentage of patients from the insulin pen users group (95.2\%) found the method easy to use as compared to only (46.7\%) among insulin syringe users. ${ }^{9}$ The primary advantage of a simpler insulin delivery device is increased adherence and persistence with therapy. This was reflected in the safety question set by documenting missed dosing during the previous 5 days prior to the interview. This increase in adherence has been demonstrated with pen devices previously among those who switch from vials to pen devices and among older patients using pen devices. ${ }^{12,13}$

Patients using a pen device reported less pain during insulin injection, fewer incidents of bruising over the skin and minimal hypoglycaemic episodes, making the pen safer to use. These results were in concordance with a study performed in Lebanon.11 Another open-label, crossover study comparing safety profiles of insulin pen versus conventional vial/ syringe for insulin injection in patients with diabetes mellitus showed similar results. ${ }^{14}$ We included hypoglycaemia episodes in the safety questionnaire as a previous study by Xie et al. has shown lower rates of hypoglycaemia when basal insulin (injection glargine) was administered with a pen device, as compared to vials. ${ }^{15}$

Patients using a pen device also reported them to be convenient to use on trips and outside the home, with less time and fewer steps involved in the injection process. The results were similar to those of Korytkowski et al., in which $85 \%$ of patients considered the use of pen to be more comfortable in public as compared to only $9 \%$ of patients using syringe device. ${ }^{14}$
Table 5: Mean simplicity, safety and convenience scores

\begin{tabular}{|l|l|l|l|}
\hline & $\begin{array}{l}\text { Syringe users } \\
\text { (mean } \pm \text { SD) }\end{array}$ & $\begin{array}{l}\text { Pen users } \\
\text { (Mean } \pm \text { SD) }\end{array}$ & (p-value) \\
\hline Total simplicity score & $9.78 \pm 1.43$ & $5.31 \pm 0.51$ & 0.0001 \\
\hline Total safety score & $8.09 \pm 2.02$ & $5.4 \pm 0.89$ & 0.0001 \\
\hline Total convenience score & $8.67 \pm 0.56$ & $4.13 \pm 1.04$ & 0.0001 \\
\hline
\end{tabular}

SD = standard deviation.

Only $2.2 \%$ of insulin syringe users were maintaining an optimal $\mathrm{HbA}_{1} \mathrm{C}$ level (6.0-7.5\%) as compared to $22.2 \%$ among the insulin pen users group, which was ten times higher. This is likely related to higher daily dose of insulin use among pen users and an increase in use of analogue insulins and unlikely to be related directly to pen use. However, in a study published in 2014, Xie et al. retrospectively demonstrated an improved $\mathrm{HbA}_{1} \mathrm{C}$ control among patients who were administered insulin glargine with a pen device compared to those who were prescribed the same insulin in vials. ${ }^{15}$

Almost $60 \%$ of individuals who were using a pen device for insulin delivery were males $(p=0.140)$ and the majority of patients in the insulin syringe group had been using insulin syringes for over 10 years $(p=0.79)$. These results could be a consequence of illiteracy and lack of awareness regarding insulin pens and poor health education in the general population, especially among women.

The average expenditure on insulin therapy among the insulin pen users group was three times higher than those using insulin syringes. This could be due to the high average amount of insulin units administered per day among pen users as compared to insulin syringe users. Moreover, among the different types of insulin used, analogue insulins were used in a greater proportion of patients from the pen group, which is costly, hence increasing the cost of therapy using a pen device. A large retrospective cohort of over 1,300 managed care patients using pen devices compared to vials suggested that the increased drug and device costs did not lead to an overall increase in total diabetes-related healthcare costs. ${ }^{15}$

\section{Limitations of the study}

The major limitation of this study is that the questionnaire was a newly developed one and has not been previously validated in other studies. The questionnaire was also only available in English and therefore had to be administered by the investigator himself, which could potentially allow for bias in the scoring. Although there was statistically significant difference in the various scores, the clinical meaningfulness of this is still debatable. We have therefore put the components of the question sets for the reader to make their own conclusion. The $\mathrm{HbA}_{1} \mathrm{C}$ values were not taken at the time of administration of the questionnaire but a recorded value closest to the interview. The difference in the type of insulin used and the dosing would also be among the many reasons for a statistical difference in $\mathrm{HbA}_{1} \mathrm{C}$ among pen users compared to syringe users.

\section{Conclusion}

In this study, more patients reported pen devices to be simpler, safer and convenient to use as compared to a syringe device. Insulin pen use was associated with better glycaemic control as compared to insulin syringe users group. Monthly expenditure on treatment among the insulin pen users group was three times higher as compared to the insulin syringe users group, which could be explained by the higher number of insulin 
units administered among pen users and a greater use of analogue insulins, which are more expensive. Better awareness is needed regarding the benefits of the insulin pen device over the syringe device among the population, especially women.
1. Guariguata L, Whiting DR, Hambleton I, et al. Global estimates of diabetes prevalence for 2013 and projections for 2035 Diabetes Res Clin Pract. 2014:103:137-49.

2. International Diabetes Federation. IDF Diabetes Atlas, 8th edn. Brussels, Belgium: International Diabetes Federation, 2017. Available at: Wum diabetesatlas org (accessed 20 November Avallable

3. American Diabetes Association. Standards of Medical Care in Diabetes-2014. Diabetes Care. 2014;37(Suppl. 1): S14-S80.

4. Koro CE, Bowlin SJ, Bourgeois N, Fedder DO. Glycemic contro from 1988 to 2000 among US adults diagnosed with type 2 diabetes Diabetes Care. 2004:27:17-20.

5. Okazaki K, Goto M, Yamamoto T, et al. Barriers and facilitators in relation to starting insulin therapy in type 2 diabetes. Diabetes. 1999;48:SA319.

6. Jha S, Panda M, Kumar S, et al. Psychological insulin resistance in patients with type 2 diabetes. J Assoc Physicians India. 2015;63:33-9.
7. Brunton S. Insulin delivery systems: reducing barriers to insulin therapy and advancing diabetes mellitus treatment. Am J Med. 2008:121:S35-41

8. Tandon N, Kalra S, Balhara YP, et al. Forum for injection technique and therapy expert recommendations, India: The ndian recommendation . Caman WH, Khreis NA, Kabbara WK Simpic Ramadan WH, Kheis NA, Kabbara WK. Simplicity, safety, and acceptability of insulin pen use versus the conventional via/ syringe device in patients with type 1 and type 2 diabetes mellitus in Lebanon. Patient Prefer Adherence. 2015;9:517.

10. Hauser ST, Pollets D. Psychological aspects of diabetes mellitus: A critical review. Diabetes Care. 1979;2:227-32.

11. Bradley C, Todd C, Gorton T, et al. The development of an individualized questionnaire measure of perceived impact of diabetes on quality of life: the ADDQOL. Qual Life Res. 1999;8:79-91.

12. Lin Xie, Steve Zhou, Wenhui Wei, et al. Does pen help? A real- world outcomes study of switching from vial to disposable pen among insulin glargine-treated patients with type 2 diabetes mellitus. Diabetes Technol Ther. 2013;15:230-6.

13. Slabaugh SL Bouchard JR, LiY et al. Characteristics Relating to Adherence and Persistence to Basal Insulin Regimens among Elderly Insulin-Naive Patients with Type 2 Diabetes: Pre-Filled Pens versus Vils/Syringes. Adv Ther. 2015,32.1206-21. Konytkowski M, Bell D, Jacobsen C, Suwannasari R. FlexPen ${ }^{\oplus}$ Study Team. A multicenter, randomized, open-label, comparative, two-period crossover trial of preference, efficacy, and safety profiles of a prefilled, disposable pen and conventional vial/syringe for insulin injection in patients with type 1 or 2 diabetes mellitus. Clin Ther. 2003;25:2836-48. 15. Xie L, Zhou S, Pinsky BW, et al. Impact of initiating insulin glargine disposable pen versus vial/syringe on real-world glycemic outcomes and persistence among patients with type 2 diabetes mellitus in a large managed care plan: a claims database analysis. Diabetes Technol Ther. 2014:16: 567-75. 